\title{
Hierarchical Active Power Control of DFIG-based Wind Farm with Distributed Energy Storage Systems based on ADMM
}

\author{
Huang, Sheng; Wu, Qiuwei; Guo, Yifei; Rong, Fei
}

Published in:

IEEE Transactions on Sustainable Energy

Link to article, DOI:

10.1109/TSTE.2019.2929820

Publication date:

2020

Document Version

Peer reviewed version

Link back to DTU Orbit

Citation (APA):

Huang, S., Wu, Q., Guo, Y., \& Rong, F. (2020). Hierarchical Active Power Control of DFIG-based Wind Farm with Distributed Energy Storage Systems based on ADMM. IEEE Transactions on Sustainable Energy, 11(3), 1528-1538. https://doi.org/10.1109/TSTE.2019.2929820

\section{General rights}

Copyright and moral rights for the publications made accessible in the public portal are retained by the authors and/or other copyright owners and it is a condition of accessing publications that users recognise and abide by the legal requirements associated with these rights.

- Users may download and print one copy of any publication from the public portal for the purpose of private study or research.

- You may not further distribute the material or use it for any profit-making activity or commercial gain

- You may freely distribute the URL identifying the publication in the public portal 


\title{
Hierarchical Active Power Control of DFIG-based Wind Farm with Distributed Energy Storage Systems based on ADMM
}

\author{
Sheng Huang, Qiuwei Wu*,Yifei Guo, Fei Rong
}

\begin{abstract}
A hierarchical active power control (HAPC) scheme based on the alternating direction method of multipliers (ADMM) is proposed for doubly-fed induction generator (DFIG)-based wind farms with distributed energy storage systems (ESSs). The wind farm controller optimizes the active power references for DFIG-based wind turbines (WTs) and ESSs inside the wind farm, and the aim is to minimize fatigue loads by minimizing variations of thrust force and shaft torque of WTs while tracking the dispatch command from the transmission system operator (TSO). Moreover, ESSs management is considered in the central controller and WT controllers. The solution method based on the ADMM with fast convergence is used to solve the model predictive control (MPC) optimization problem in a hierarchical manner without loss of optimality. With the ADMM, the control task is distributed to WT controllers, and the computation burden of the central wind farm controller can be efficiently reduced. A wind farm with 30 DFIG WTs was used to validate the control performance of the proposed HAPC scheme.
\end{abstract}

Index Terms-ADMM, DFIG, ESS, fatigue loads, hierarchical, MPC, wind farm.

\section{INTRODUCTION}

$\mathbf{W}$ Ind energy has achieved rapid development and growth [1]. Due to strong fluctuations of wind power, integration of wind power at high penetration levels creates significant challenges to power system operation [2], [3]. The energy storage system (ESS) has attracted considerable attention in electric power systems [4], which can be integrated into wind power generation to comply with specific grid connection requirements [5].

With flexible charge/discharge characteristics, the ESS is considered as an effective tool for enhancing the flexibility and controllability of a wind farm. The ESS can efficiently maintain the safe operation of power grid, balance supply and demand sides, enhance fault ride-through ability, and damp short-term power oscillation [6]. The ESS for wind farms can be centralized [7], [8] or distributed [9]- [10]. The centralized ESS can be divided into aggregated ESS [11], [12] and modular multilevel converter (MMC)-based ESS [13],

Corresponding author: Qiuwei Wu (e-mail: qw@elektro.dtu.dk).

S. Huang and Q. Wu are with Center for Electric Power and Energy (CEE), Department of Electrical Engineering, Technical University of Denmark (DTU), Kgs. Lyngby, 2800 Denmark. (e-mail: huang98123@163.com, qw@elektro.dtu.dk).

Y. Guo is with Key Laboratory of Power System Intelligent Dispatch and Control of Ministry of Education, Shandong University, Jinan 250061, China China. (e-mail: yfguo-sdu@163.com).

F. Rong is with electrical engineering in the College of Electrical and information engineering, Hunan University , Changsha 410082, China.(e-mail: rf_hunu@126.com).
[14]. For the wind farm with distributed ESSs, each ESS is placed at the DC link of the wind turbine (WT) converter by using a half-bridge DC/DC converter. With the wind farm growing both in number and size, the cost of converters with the distributed ESS is comparatively lower than the aggregated ESS. The robustness of the distributed ESSs is better than the MMC-based centralized ESS. As such, the distributed ESSs is suitable for large-scale wind farms. Several control schemes have been proposed to coordinate the WT with distributed ESS to improve the generation capability, enhance performance of the ESS, and smooth the output power [15], [16]. However, few studies exist on the optimal control scheme of a wind farm with distributed ESSs.

The active and reactive power output of the wind farm should follow the dispatch command from the transmission system operator (TSO). In conventional wind farm control strategies, wind farm controller dispatches active and reactive power references to WTs according to their available wind power, which has the advantage of simple implementation. In recent years, the optimization-based control strategies have been developed to improve the control performance [17]. The reduction of fatigue loads is one of the important issues in wind farm control. WTs are fatigue critical machines. The fatigue of many of components (i.e., blades, towers, and shafts) of the WTs has to be considered by the WT designer [18]. Otherwise, WTs may fail due to the long term and repeated fatigue damage caused by fluctuant wind power, which creates micro cracks in the WT material. When a wind farm operates in the de-load mode, it can vary its power production in response to wind speed fluctuations. The active power output can be redistributed among WTs according to local wind conditions [19]. If a lower fatigue load can be achieved, a lighter WT can be used, which directly leads to reduction of WT prices and extended WT service time [20], [21].

The fatigue load minimization of WTs has motivated numerous studies. In [22], [23], a centralized wind farm controller was designed based on minimizing the destructive fluctuations of torque and generator speed while tracking the dispatch command. A coordinated control scheme for wind farms was proposed in [24]. The objective is to minimize fluctuations of the shaft torque and thrust force. In [25], a combined active and reactive power based on model predictive control (MPC) was proposed, which aims to reduce fatigue loads experienced by WTs while keeping bus voltages inside wind farm within the feasible range. A fatigue load sensitivity-based optimal active power dispatch strategy was proposed in [26] to reduce 
the computation burden of the wind farm controller. Fatigue load sensitivity is calculated in the WT controller and the optimization problem of the wind farm control is solved in a centralized manner.

There is no study on fatigue loads minimization of a wind farm with distributed ESSs. With distributed ESSs, the wind farm controller can regulate the WTs more flexibly. Moreover, considering the stochastic and intermittent nature of wind energy, the time scale of optimal active power control for fatigue load minimization is in seconds. With the development of large-scale wind power projects, the large-scale wind farm central controller might not be able to solve a large-scale optimization problem with large-scale constraints in seconds due to the high computation burden of the central controller. Therefore, a hierarchical active power control (HAPC) scheme based on the alternating direction method of multipliers (ADMM) is proposed to reduce the computation burden of the wind farm central controller. The ADMM algorithm has been widely used in power systems [27], [28].

In this paper, the DFIGs, converters, ESSs are optimally coordinated based on the MPC to reduce fatigue loads by minimizing variations of the thrust force and shaft torque of WTs while tracking the dispatch command and maintaining the state-of-charge (SOC) of ESSs within a specified range. The solution method based on ADMM with fast convergence is used to solve the MPC problem in a hierarchical manner.

The main contribution of this paper is the HAPC scheme based on the ADMM for large-scale wind farms with distributed ESSs. The DFIGs, converters, ESSs dynamic control models are taken into consideration to achieve better control performance. The HAPC can efficiently reduce the computation burden of the central controller. With the ADMM algorithm, the MPC-based large-scale optimization problem is distributed among the central unit and local WT controllers and solved in parallel. The HAPC guarantes the optimality of the solution, and enhances system flexibility, robustness, and computational efficiency. Moreover, with the hierarchical optimal solution method, the central agent and local agent exchange the updated global and local variables in the ADMM, instead of explicit measurements and set-points. The protection of information privacy is improved.

The paper is organized as follows. Section II provides a overview of the proposed HAPC scheme. The model of the DFIG wind farm equipped with distributed ESSs is presented in Section III. The solution method based on the ADMM is described in Section IV. Simulation results are presented and discussed in Section V, followed by conclusions.

\section{Control Scheme Architecture}

\section{A. Wind Farm Configuration}

Fig. 1 shows a typical configuration of a wind farm connected to an external AC grid through a transmission cable. The on-load tap changer (OLTC) transformer is at the point of connection (POC). The medium voltage (MV) side is connected to several feeders. In addition, several WTs are connected to a feeder. The ESS at the WT consists of an energy storage unit (ESU) and a DC/DC converter connected to the
DC link. The active and reactive power of the DFIG can be controlled independently.

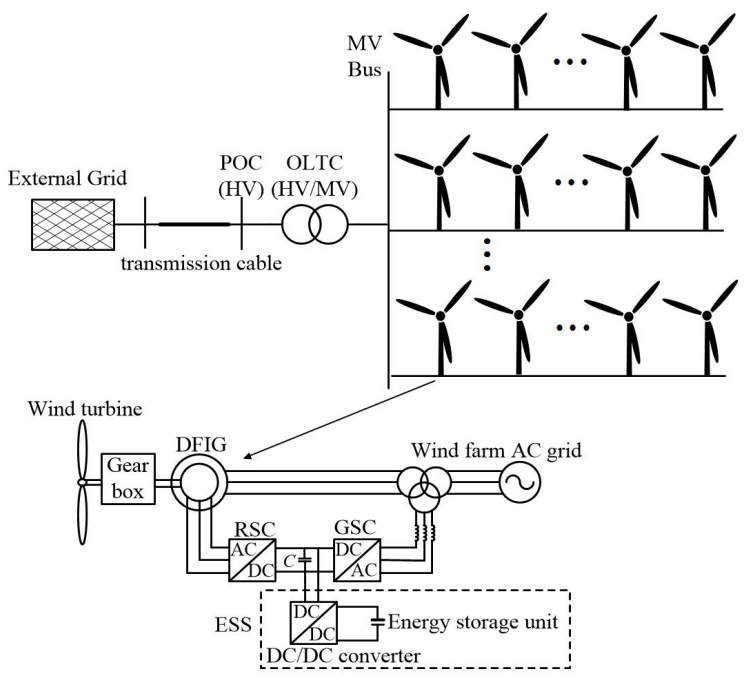

Fig. 1. Configuration of a wind farm.

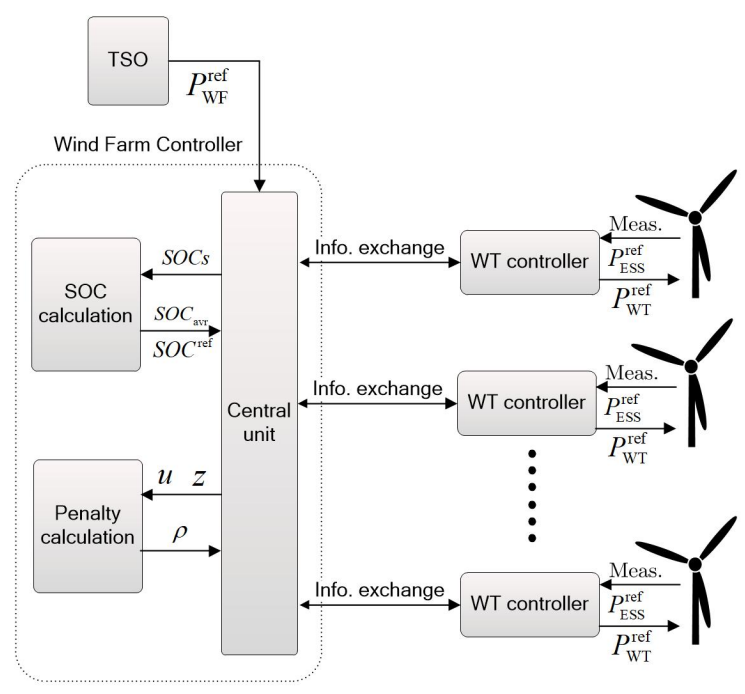

Fig. 2. Control structure.

\section{B. Control Concept}

Fig. 2 shows the structure of the proposed control scheme. The control scheme is designed in a hierarchical manner based on the ADMM. The TSO sends the dispatch command to the wind farm central controller. The wind farm central controller consists of a SOC calculation block, penalty calculation block, and central unit. The SOC calculation block is used to calculate a SOC reference for the distributed ESSs. The penalty calculation block is used to dynamically regulate the penalty of the ADMM according to global and local variables at each iteration step, which can improve the convergence and make the performance less dependent on the initial choice of the penalty parameter. The central unit is used to solve a MPCbased augmented Lagrangian optimization problem with the 
equality constraints. The global variables, local variables, dual variables and the ESSs SOC are exchanged between the central unit and local WT controllers through the communication network. The task of the WT controller is to solve a small-scale optimization problem with small-scale inequality constraints. With part of calculation distributed among individual WT controllers, the computation burden of the wind farm controller can be reduced efficiently.

\section{DFIG WIND POWER SYSTEM MODEL}

\section{A. RSC model}

The rotor-side converter (RSC) control scheme is shown in Fig. 3 [10]. The operation is achieved by regulating rotor current in a stator-flux-oriented and synchronously rotating reference frame to decouple active and reactive power control. The d-axis of the reference frame is oriented along the statorflux-oriented vector.

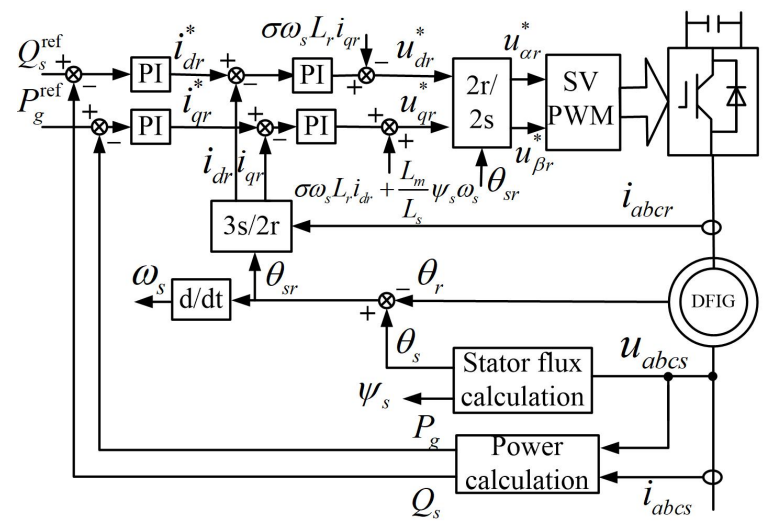

Fig. 3. The RSC control scheme

The DFIG active power output $P_{\mathrm{g}}$ can be expressed by,

$$
P_{\mathrm{g}}=P_{\mathrm{s}}+P_{\mathrm{r}}
$$

where $P_{\mathrm{s}}$ and $P_{\mathrm{r}}$ are the active power from the stator and rotor, respectively. This study only considers the active power of the wind farm. Then, $P_{\mathrm{s}}$ and $P_{\mathrm{r}}$ can be expressed as [10], [29],

$$
\begin{gathered}
P_{\mathrm{s}}=\frac{3 L_{\mathrm{m}} \psi_{\mathrm{m}} \omega_{\mathrm{s}}}{2 L_{\mathrm{s}}} i_{\mathrm{qr}} \\
P_{\mathrm{r}}=-s_{\mathrm{g}} P_{\mathrm{s}}
\end{gathered}
$$

where $s_{\mathrm{g}}$ is the slip ratio, $L_{\mathrm{m}}$ is the mutual inductance of the stator and the rotor, $\psi_{\mathrm{m}}$ is the stator flux, $\omega_{\mathrm{s}}$ is the system angular speed, and $L_{\mathrm{s}}$ is the stator inductance. Generally, the dynamic performance of the inner current loop can be described as a first-order lag function. Thus, the RSC model can be simplified as shown in Fig. 4.

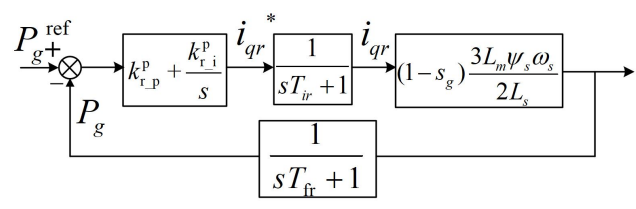

Fig. 4. Active power control loop of the DFIG
$P_{\mathrm{g}}^{\mathrm{ref}}$ is the active power reference for the DFIG, and $P_{\text {int }}$ is the integral of the error between $P_{\mathrm{g}}^{\text {ref }}$ and $P_{\mathrm{g}}$. Then, the incremental state space model of the RSC can be obtained as,

$$
\begin{aligned}
\Delta i_{\mathrm{qr}} & =\frac{1}{1+s T_{\mathrm{ir}}}\left(k_{\mathrm{r}_{-} \mathrm{p}}^{\mathrm{p}}+\frac{k_{\mathrm{r}_{\mathrm{i}}}^{\mathrm{p}}}{s}\right)\left(\Delta P_{\mathrm{g}}^{\mathrm{ref}}-\Delta P_{\mathrm{g}}\right) \\
\Delta P_{\mathrm{g}} & =\frac{1}{1+s T_{\mathrm{fr}}}\left(\left(1-s_{\mathrm{g}}\right) \frac{3 L_{\mathrm{m}} \psi_{\mathrm{m}} \omega_{\mathrm{s}}}{2 L_{\mathrm{s}}}\right) \Delta i_{\mathrm{qr}} \\
\Delta P_{\mathrm{int}} & =\frac{\Delta P_{\mathrm{g}}^{\mathrm{ref}}-\Delta P_{\mathrm{g}}}{s}
\end{aligned}
$$

where $k_{\mathrm{r}_{-} \mathrm{p}}^{\mathrm{p}}$ and $k_{\mathrm{r}_{-} \mathrm{i}}^{\mathrm{p}}$ are the proportional and integral gains of the PI controller of the outer loop, respectively, $T_{\mathrm{ir}}$ is the time constant of the inner loop, and $T_{\text {fr }}$ is the active power filter time constant of the DFIG.

\section{B. ESS model}

The topology of the DC/DC converter and its DC/DC control diagram are shown in Fig. 5. The converter can operate in the buck or boost mode depending on the status of the two IGBT switches. The active power reference of the ESS is compared with the actual measurement. The error between these signals is used as the reference for the PI controller to generate the inner loop current references. The duty cycle of the IGBT is obtained by the inner loop PI controller. Thus, the active power control loop of the DC/DC converter can be simplified as shown in Fig. 6 [30].

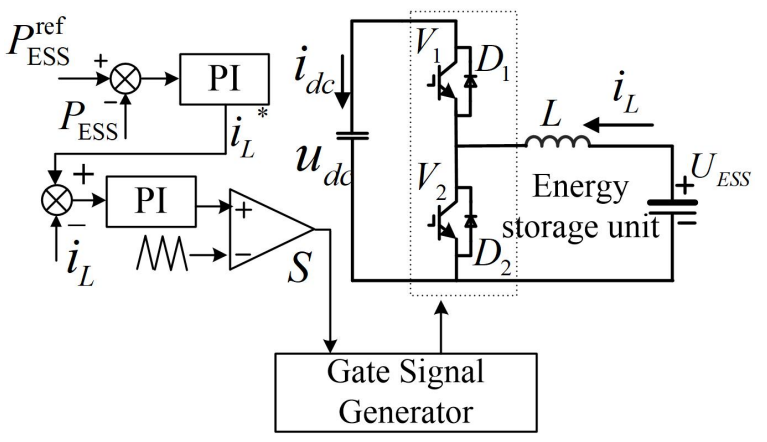

Fig. 5. Topology and control diagram of the DC/DC converter

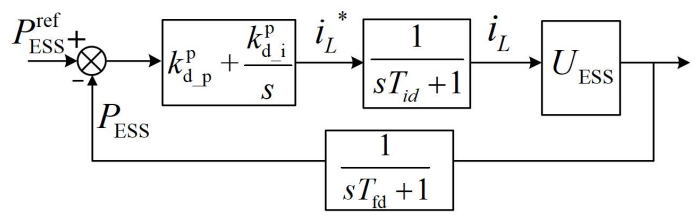

Fig. 6. Active power control loop of the DC/DC converter

The energy stored in the ESS $C_{\mathrm{ESS}}$ can be expressed by,

$$
C_{\mathrm{ESS}}=C_{\mathrm{ESS}}^{0}-\int P_{\mathrm{ESS}} d t
$$

where $C_{\mathrm{ESS}}^{0}$ is the initial energy, and $P_{\mathrm{ESS}}$ is the charge/discharge power of the ESS.

$P_{\mathrm{ESS}}^{\mathrm{ref}}$ is the active power reference for the ESS, and $P_{\mathrm{ESS}}^{\mathrm{int}}$ is the integral of the error between $P_{\mathrm{ESS}}^{\mathrm{ref}}$ and $P_{\mathrm{ESS}}$. Then, the 
incremental state space model of the DC/DC converter can be obtained as,

$$
\begin{aligned}
\Delta \dot{C}_{\mathrm{ESS}} & =-\Delta P_{\mathrm{ESS}}-\Delta P_{\mathrm{ESS}}^{0} \\
\Delta i_{\mathrm{L}} & =\frac{1}{1+s T_{\mathrm{id}}}\left(k_{\mathrm{d} \_\mathrm{p}}^{\mathrm{p}}+\frac{k_{\mathrm{d} \_\mathrm{i}}^{\mathrm{i}}}{s}\right)\left(\Delta P_{\mathrm{ESS}}^{\mathrm{ref}}-\Delta P_{\mathrm{ESS}}\right) \\
\Delta P_{\mathrm{ESS}} & =\frac{1}{1+s T_{\mathrm{fd}}} U_{\mathrm{ESS}} \Delta i_{\mathrm{L}} \\
\Delta P_{\mathrm{int}} & =\frac{\Delta P_{\mathrm{ESS}}^{\mathrm{ref}}-\Delta P_{\mathrm{ESS}}}{s}
\end{aligned}
$$

where $k_{\mathrm{d}_{\mathrm{p}} \mathrm{p}}^{\mathrm{p}}$ and $k_{\mathrm{d} \_\mathrm{i}}^{\mathrm{p}}$ are the proportional and integral gains of the PI controller of the outer loop, respectively, $T_{\mathrm{id}}$ is the time constant of the inner loop, and $T_{\mathrm{fd}}$ is the active power filter time constant of the DC/DC converter.

Batteries have losses caused by charging and discharging activities. Based on (7), the energy stored in the ESS can be rewritten as,

$C_{\mathrm{ESS}}=C_{\mathrm{ESS}}^{0}+\left(1-\eta_{\mathrm{L}}\right) \int P_{\mathrm{ESS}}^{\mathrm{ch}} d \mathrm{t}-\left(1+\eta_{\mathrm{L}}\right) \int P_{\mathrm{ESS}}^{\mathrm{dis}} d \mathrm{t}$

where $\eta_{\mathrm{L}}$ is the charge/discharge loss coefficient, $P_{\mathrm{ESS}}^{\mathrm{ch}} \geq 0$ is the ESS charge power, and $P_{\mathrm{ESS}}^{\mathrm{dis}} \geq 0$ is the ESS discharge power, and $t^{\mathrm{ch}} P_{\mathrm{ESS}}^{\mathrm{ch}}+t^{\mathrm{dis}} P_{\mathrm{ESS}}^{\mathrm{dis}}=P_{\mathrm{ESS}}$, and $t^{\mathrm{ch}}$ and $t^{\text {dis }}$ are the binary variables to represent the state of the ESS energy flow (charge or discharge), $t^{\text {ch }}+t^{\text {dis }} \leq 1$. At each control period, the ESS operates in either the charge mode or discharge mode.

By combining (9)-(12), the state space model of the ESS in a matrix form can be represented as,

$$
\begin{aligned}
\Delta \dot{x}_{\mathrm{E}} & =\boldsymbol{A}_{\mathrm{E}} \Delta x_{\mathrm{E}}+\boldsymbol{B}_{\mathrm{E}} \Delta u_{\mathrm{E}}+\boldsymbol{E}_{\mathrm{E}} \\
\Delta y_{\mathrm{E}} & =\boldsymbol{C}_{\mathrm{E}} \Delta x_{\mathrm{E}}
\end{aligned}
$$

where $\Delta x_{\mathrm{E}}=\left[\Delta C_{\mathrm{ESS}}, \Delta P_{\mathrm{ESS}}^{\mathrm{ch}}, \Delta P_{\mathrm{ESS}}^{\mathrm{int}, \mathrm{ch}}, \Delta i_{\mathrm{L}}^{\mathrm{ch}}, \Delta P_{\mathrm{ESS}}^{\mathrm{dis}}\right.$, $\left.\Delta P_{\mathrm{ESS}}^{\mathrm{int}, \text { dis }}, \Delta i_{\mathrm{L}}^{\mathrm{dis}}\right]^{T}, \Delta u_{\mathrm{E}}=\left[\Delta P_{\mathrm{ESS}}^{\mathrm{ref}, \mathrm{ch}}, \Delta P_{\mathrm{ESS}}^{\mathrm{ref}, \mathrm{dis}}, t^{\mathrm{ch}}, t^{\mathrm{dis}}\right]^{T}$, and $\Delta y_{\mathrm{E}}=\Delta C_{\mathrm{ESS}}, \boldsymbol{C}_{\mathrm{E}}=[1,0,0,0,0,0,0]$,

$$
\begin{aligned}
& \boldsymbol{A}_{\mathrm{E}}=\left[\begin{array}{ccccccc}
0 & 1-\eta_{\mathrm{L}} & 0 & 0 & -1-\eta_{\mathrm{L}} & 0 & 0 \\
0 & -\frac{1}{T_{\mathrm{fd}}} & 0 & \frac{U_{\mathrm{ESS}}}{T_{\mathrm{fd}}} & 0 & 0 & 0 \\
0 & -1 & 0 & 0 & 0 & 0 & 0 \\
0 & -\frac{k_{\mathrm{d}_{-} \mathrm{p}}^{\mathrm{p}}}{T_{\mathrm{id}}} & \frac{k_{\mathrm{d}}^{\mathrm{p}} \mathrm{i}}{T_{\mathrm{id}}} & -\frac{1}{T_{\mathrm{id}}} & 0 & 0 & 0 \\
0 & 0 & 0 & 0 & -\frac{1}{T_{\mathrm{fd}}} & 0 & \frac{U_{\mathrm{ESS}}}{T_{\mathrm{fd}}} \\
0 & 0 & 0 & 0 & -1 & 0 & 0 \\
0 & 0 & 0 & 0 & -\frac{k_{\mathrm{d} \_\mathrm{p}}^{\mathrm{p}}}{T_{\mathrm{id}}} & \frac{k_{\mathrm{d} \mathrm{i}}^{\mathrm{p}}}{T_{\mathrm{id}}} & -\frac{1}{T_{\mathrm{id}}}
\end{array}\right] \\
& \boldsymbol{B}_{\mathrm{E}}=\left[\begin{array}{cccc}
0 & 0 & K^{\mathrm{ch}} & K^{\mathrm{dis}} \\
0 & 0 & 0 & 0 \\
1 & 0 & 0 & 0 \\
k_{\mathrm{d} \_\mathrm{p}}^{\mathrm{p}} & 0 & 0 & 0 \\
\hline T_{\mathrm{id}} & 0 & 0 & 0 \\
0 & 1 & 0 & 0 \\
0 & k_{\mathrm{d} \_\mathrm{p}}^{\mathrm{p}} & 0 & 0 \\
0 & \frac{T_{\mathrm{id}}}{T_{\mathrm{di}}} & &
\end{array}\right] \\
& \boldsymbol{E}_{\mathrm{E}}=\left[\left(1-\eta_{\mathrm{L}}\right) P_{\mathrm{ESS}}^{\mathrm{ch}, 0}-\left(1+\eta_{\mathrm{L}}\right) P_{\mathrm{ESS}}^{\mathrm{dis}, 0}, 0,0,0,0,0,0\right]^{T}
\end{aligned}
$$

where $K^{\mathrm{ch}}$ and $K^{\text {dis }}$ are the parameters, which depend on the initial state of ESS energy flow. When the ESS is operated in the charge mode at the initial operation point, $K^{\mathrm{ch}}=0$, $K^{\text {dis }}=-\left(1-\eta_{\mathrm{L}}\right) P_{\mathrm{ESS}}^{\mathrm{ch}, 0}$. When the ESS is operated in the discharge mode at the initial operation point, $K^{\mathrm{ch}}=(1+$ $\left.\eta_{\mathrm{L}}\right) P_{\mathrm{ESS}}^{\mathrm{dis}, 0}, K^{\text {dis }}=0$.
Based on [31], the battery degradation cost model is taken into consideration. In this mode, the SOC, ambient temperature, capital cost, and rated cycle life of the ESSs are considered. The ESS degradation cost model is expressed as,

$B C=\frac{\left(P_{\mathrm{ESS}}^{\mathrm{ch}}+P_{\mathrm{ESS}}^{\mathrm{dis}}\right) \mu_{\mathrm{ESS}} \gamma_{\mathrm{ESS}} \Delta T_{\mathrm{c}}}{a_{1}\left[a_{2}\left(1-S O C^{0}\right)+a_{3}\right] e^{\left(a_{4} T_{\mathrm{ESS}}\right)} E_{\mathrm{R}}\left(1-S O C^{\mathrm{ref}}\right)}$

where $\mu_{\mathrm{ESS}}$ is the capital cost of the ESS, $\gamma_{\mathrm{ESS}}$ is the rated cycle life of the ESS, $\triangle T_{\mathrm{c}}$ is the control period, $S O C^{0}$ is the initial SOC level at the operation point, $S O C^{\text {ref }}$ is the SOC reference, $T_{\mathrm{ESS}}$ is the ESS temperature, $E_{\mathrm{R}}$ is the capacity of the ESS, and $a_{1}, a_{2}, a_{3}$, and $a_{4}$ are the coefficients of the ESS life cycle.

\section{WT Mechanical System Model}

The nonlinear variable speed WT system developed by National Renewable Energy Laboratory (NREL) is used in this study [32]. With the analytical approach in [33] and the RSC model, the incremental state-space DFIG WT model around an operating point can be formulated as,

$$
\begin{aligned}
\Delta \dot{x}_{\mathrm{w}} & =\boldsymbol{A}_{\mathrm{w}} \Delta x_{\mathrm{w}}+\boldsymbol{B}_{\mathrm{w}} \Delta u_{\mathrm{w}}+\boldsymbol{E}_{\mathrm{w}}, \\
\Delta y_{\mathrm{w}} & =\boldsymbol{C}_{\mathrm{w}} \Delta x_{\mathrm{w}},
\end{aligned}
$$

where $\Delta x_{\mathrm{w}}=\left[\Delta P_{\mathrm{g}}, \Delta P_{\mathrm{int}}, \Delta i_{\mathrm{qr}}, \Delta \beta^{\text {ref }}, \Delta \beta, \Delta \omega_{g}, \Delta \omega_{\mathrm{f}}\right]^{T}$, $\Delta u=\Delta P_{\mathrm{g}}^{\text {ref }}$, and $\Delta y_{\mathrm{w}}=\left[\Delta T_{\mathrm{s}}, \Delta F_{\mathrm{t}}, \Delta P_{\mathrm{g}}\right]^{T}$. The state-space matrixes are,

$$
\begin{aligned}
& \boldsymbol{A}_{\mathrm{W}}=\left[\begin{array}{ccccccc}
-\frac{1}{T_{\mathrm{fr}}} & 0 & K_{\mathrm{RSC}} & 0 & 0 & 0 & 0 \\
-1 & 0 & 0 & 0 & 0 & 0 & 0 \\
-\frac{k_{\mathrm{r}} \mathrm{p}}{T_{\mathrm{ir}}} & \frac{k_{\mathrm{r}-\mathrm{i}}^{\mathrm{p}}}{T_{\mathrm{ir}}}-\frac{1}{T_{\mathrm{ir}}} & 0 & 0 & 0 & 0 \\
0 & 0 & 0 & 0 & 0 & \frac{K_{p}}{T_{\mathrm{f}}} & -\frac{K_{p}}{T_{\mathrm{f}}}+K_{i} \\
0 & 0 & 0 & \frac{K_{\mathrm{c}, 0}}{T_{\theta} K_{\mathrm{c}, 0}^{\mathrm{ref}}} & -\frac{1}{T_{\theta}} & 0 & 0 \\
-\frac{\eta_{g}^{2}}{\mu_{\mathrm{g}} J_{\mathrm{t}} \omega_{\mathrm{f}, 0}} & 0 & 0 & 0 & \frac{\eta_{g} K_{\beta T}}{J_{\mathrm{t}}} & \frac{\eta_{g} K_{\omega T}}{J_{\mathrm{t}}} & \frac{\eta_{g}^{2} P_{\mathrm{g}, 0}}{\mu_{\mathrm{g}} J_{\mathrm{t}} \omega_{\mathrm{f}, 0}^{2}} \\
0 & 0 & 0 & 0 & 0 & \frac{1}{T_{\mathrm{f}}} & -\frac{1}{T_{\mathrm{f}}}
\end{array}\right] \\
& \boldsymbol{B}_{\mathrm{w}}=\left[\begin{array}{c}
0 \\
1 \\
\frac{k_{\mathrm{r}}^{\mathrm{p}}}{T_{\mathrm{ir}}} \\
0 \\
0 \\
0 \\
0
\end{array}\right], \boldsymbol{E}_{\mathrm{w}}=\left[\begin{array}{c}
0 \\
0 \\
0 \\
K_{i}\left(\omega_{\mathrm{f}, 0}-\omega_{g}^{\text {rated }}\right) \\
\frac{K_{\mathrm{c}, 0}}{T_{\theta}}\left(\theta_{0}^{\text {ref }}-\theta_{0}\right) \\
\frac{\eta_{g}}{J_{\mathrm{t}}}\left(T_{\mathrm{a}, 0}-\eta_{g} T_{g, 0}\right) \\
0
\end{array}\right] \\
& \boldsymbol{C}_{\mathrm{w}}=\left[\begin{array}{ccccccc}
\frac{\eta_{g} J_{r}}{\mu_{\mathrm{g}} J_{t} \omega_{f, 0}} & 0 & 0 & 0 & \frac{\eta_{g}^{2} J_{g} K_{\beta T}}{J_{\mathrm{t}}} & \frac{\eta_{g}^{2} J_{g} K_{\omega T}}{J_{\mathrm{t}}} & -\frac{\eta_{g} J_{\mathrm{r}} P_{\mathrm{g}, 0}}{\mu_{\mathrm{g}} J_{t} \omega_{\mathrm{f}, 0}^{2}} \\
0 & 0 & 0 & 0 & K_{\beta F} & K_{\omega F} & 0 \\
1 & 0 & 0 & 0 & 0 & 0 & 0
\end{array}\right]
\end{aligned}
$$

where $\theta$ is the pitch angle of the WT, $\beta=K_{\mathrm{c}} \theta, \omega_{\mathrm{g}}$ is the measured generator speed, $\omega_{\mathrm{f}}$ is the filtered speed, $T_{s}$ is the shaft torque, $F_{\mathrm{t}}$ is the thrust force, $\eta_{g}$ is the gear box ratio, $J_{t}=J_{r}+\eta_{g}^{2} J_{g}$ is the equivalent mass by emerging the rotor mass $J_{r}$ and generator mass $J_{g}$, and $K_{p}$ and $K_{i}$ denote the proportional and integral gains of the pitch controller. $K_{\mathrm{c}, 0}=$ $K_{0}+2 K_{1} \theta_{0}$, where $K_{0}$ and $K_{1}$ are constant. $K_{\omega T}, K_{\beta T}$, $K_{\beta F}$, and $K_{\omega F}$ are the coefficients derived from the Taylor approximations of the aerodynamic torque $T_{\mathrm{a}}$ and $F_{\mathrm{t}}$ at the operating point, and $K_{\mathrm{RSC}}=\left(1-s_{\mathrm{g}}\right) \frac{3 L_{\mathrm{m}} \psi_{\mathrm{m}} \omega_{\mathrm{s}}}{2 T_{\mathrm{fr}} L_{\mathrm{s}}}$ is a coefficient. 


\section{Wind Farm Model}

Denote $\mathcal{N}_{\mathrm{T}}$ as the set of WTs inside the wind farm. The continuous state space model of the wind farm can be formulated as,

$$
\begin{aligned}
\Delta \dot{x}_{\mathrm{wf}} & =\boldsymbol{A}_{\mathrm{wf}} \Delta x_{\mathrm{wf}}+\boldsymbol{B}_{\mathrm{wf}} \Delta u_{\mathrm{wf}}+E_{\mathrm{wf}} \\
\Delta y_{\mathrm{wf}} & =\boldsymbol{C}_{\mathrm{wf}} \Delta x_{\mathrm{wf}}
\end{aligned}
$$

where

$$
\begin{gathered}
\Delta x_{\mathrm{wf}}=\left[\Delta x_{\mathrm{w}}^{1}, \Delta x_{\mathrm{E}}^{1} \ldots \Delta x_{\mathrm{w}}^{\left|\mathcal{N}_{\mathrm{T}}\right|}, \Delta x_{\mathrm{E}}^{\left|\mathcal{N}_{\mathrm{T}}\right|}\right]^{T} \\
\Delta u_{\mathrm{wf}}=\left[\Delta P_{\mathrm{g}, 1}^{\mathrm{ref}}, \Delta P_{\mathrm{ESS}, 1}^{\mathrm{ref}} \cdots, \Delta P_{\mathrm{g},\left|\mathcal{N}_{\mathrm{T}}\right|}^{\mathrm{ref}}, P_{\mathrm{ESS},\left|\mathcal{N}_{\mathrm{T}}\right|}^{\mathrm{ref}}\right]^{T} \\
\Delta y_{\mathrm{wf}}=\left[\Delta y_{\mathrm{w}}^{1}, \Delta y_{\mathrm{E}}^{1} \cdots \Delta y_{\mathrm{w}}^{\left|\mathcal{N}_{\mathrm{T}}\right|}, \Delta y_{\mathrm{E}}^{\left.\left|\mathcal{N}_{\mathrm{T}}\right|\right]^{T}}\right. \\
\boldsymbol{A}_{\mathrm{wf}}=\operatorname{diag}\left[\boldsymbol{A}_{\mathrm{w}, 1}, \boldsymbol{A}_{\mathrm{E}, 1} \cdots, \boldsymbol{A}_{\mathrm{w},\left|\mathcal{N}_{\mathrm{T}}\right|}, \boldsymbol{A}_{\mathrm{E},\left|\mathcal{N}_{\mathrm{T}}\right|}\right] \\
\boldsymbol{B}_{\mathrm{wf}}=\operatorname{diag}\left[\boldsymbol{B}_{\mathrm{w}, 1}, \boldsymbol{B}_{\mathrm{E}, 1}, \cdots, \boldsymbol{B}_{\mathrm{w},\left|\mathcal{N}_{\mathrm{T}}\right|}, \boldsymbol{B}_{\mathrm{E},\left|\mathcal{N}_{\mathrm{T}}\right|}\right] \\
\boldsymbol{E}_{\mathrm{wf}}=\operatorname{diag}\left[\boldsymbol{E}_{\mathrm{w}, 1}, \boldsymbol{E}_{\mathrm{E}, 1}, \cdots, \boldsymbol{E}_{\mathrm{w},\left|\mathcal{N}_{\mathrm{T}}\right|}, \boldsymbol{E}_{\left.\mathrm{E},\left|\mathcal{N}_{\mathrm{T}}\right|\right]}\right. \\
\boldsymbol{C}_{\mathrm{wf}}=\operatorname{diag}\left[\boldsymbol{C}_{\mathrm{w}, 1}, \boldsymbol{C}_{\mathrm{E}, 1} \cdots, \boldsymbol{C}_{\mathrm{w},\left|\mathcal{N}_{\mathrm{T}}\right|}, \boldsymbol{C}_{\left.\mathrm{E},\left|\mathcal{N}_{\mathrm{T}}\right|\right]}\right.
\end{gathered}
$$

The discrete state-space model can be derived from the continuous model, which is,

$$
\begin{aligned}
\Delta x_{\mathrm{wf}}(k+1) & =\boldsymbol{A}_{\mathrm{wf}, \mathrm{d}} \Delta x_{\mathrm{wf}}(k)+\boldsymbol{B}_{\mathrm{wf}, \mathrm{d}} \Delta u_{\mathrm{wf}}(k)+\boldsymbol{E}_{\mathrm{wf}, \mathrm{d}}, \\
\Delta y_{\mathrm{wf}}(k) & =\boldsymbol{C}_{\mathrm{wf}} \Delta x_{\mathrm{wf}}(k) .
\end{aligned}
$$

The discrete state space matrixes $\boldsymbol{A}_{\mathrm{wf}, \mathrm{d}}, \boldsymbol{B}_{\mathrm{wf}, \mathrm{d}}, \boldsymbol{E}_{\mathrm{wf}, \mathrm{d}}$ can be calculated with the method in [34].

\section{Hierarchical Control BASED ON ADMM}

\section{A. Objective Function}

The battery energy management system (BEMS) sets the power reference for each ESS inside the wind farm, in which its SOC and the mismatch between the power generated by the DFIG and the power required by the grid are collectively considered. For each ESS, the SOC should be maintained within the secure operation range, i.e.,

$$
S O C_{\min } \leq S O C_{i} \leq S O C_{\max }
$$

In this study, $S O C_{\min }$ and $S O C_{\max }$ are set as 0.3 and 0.7 , respectively. The main objective of the control strategy for the wind farm is to track the power reference while reducing fatigue loads and consider the ESSs SOC balance inside the wind farm. Two control modes are designed for different operating conditions.

\section{a. Mode 1}

If the dispatch command from the TSO is lower than the total available wind power, the wind farm operates in Mode 1. In order to facilitate the long-term stable operation of the wind farm, the SOC is limited within the range of higher than the middle SOC level. This implies that the ESSs should maintain a SOC at a high level to deal with the condition in which the total available wind power is lower than the dispatch command. The first objective is to keep the SOC level of ESSs close to the SOC reference. The second objective is to minimize the fluctuation of the shaft torque, which is transmitted through the gearbox. The oscillatory transient of the shaft torque causes microcracks in the material, which might make the component of the WT fail. The third objective is to minimize the fluctuation of the thrust force. For the tower structure, the wind turbine tower is excited by the thrust force caused by the wind flowing on the rotor. The oscillatory transient causes fatigue of the wind turbine tower. The last objective is the battery degradation cost caused by charging and discharging. Accordingly, the cost function is expressed as,

$$
\begin{gathered}
\min \sum_{i=1}^{\left|\mathcal{N}_{\mathrm{T}}\right|} \sum_{k=1}^{N_{p}}\left\|C_{\mathrm{ESS}, i}(k)-\alpha C_{\mathrm{ESS}}^{\mathrm{rated}}\right\|_{Q_{\mathrm{C}}}^{2}+\left\|\Delta T_{\mathrm{s}, i}(k)\right\|_{Q_{\mathrm{T}}}^{2} \\
\quad+\left\|\Delta F_{\mathrm{t}, i}(k)\right\|_{Q_{\mathrm{F}}}^{2}+\left\|B C_{i}(k)\right\|_{Q_{\mathrm{C}}}^{2}
\end{gathered}
$$

where $N_{p}$ is the predictive steps of the MPC, $C_{\mathrm{ESS}}^{\text {rated }}$ is the rated energy capacity of the total ESS, $\alpha$ is the reference for the SOC level, and $Q_{\mathrm{C}}$ is a weighting factor for minimizing the deviation of energy storage to its reference, and $Q_{\mathrm{T}}$ and $Q_{\mathrm{F}}$ are the weighting factors for minimizing variation of the shaft torque $T_{\mathrm{s}}$ and variation of the thrust force $F_{\mathrm{t}}$, respectively, and $Q_{\mathrm{C}}$ is the weighting factors for the ESS degradation cost.

\section{b. Mode 2}

If the dispatch command from the TSO is higher or equal to the total available wind power, the wind farm operates in Mode 2. All ESSs should release power to track the dispatch command. In this condition, to achieve fair utilization among the ESSs, the wind farm controller generates the power reference for each ESS to maintain all SOCs close to their average values. Accordingly, the cost function is expressed as,

$$
\begin{gathered}
\min \sum_{i=1}^{\left|\mathcal{N}_{\mathrm{T}}\right|} \sum_{k=1}^{N_{p}}\left\|C_{\mathrm{ESS}, i}(k)-C_{\mathrm{ESS}}^{\mathrm{avr}}\right\|_{Q_{\mathrm{C}}}^{2}+\left\|\Delta T_{\mathrm{s}, i}(k)\right\|_{Q_{\mathrm{T}}}^{2} \\
+\left\|\Delta F_{\mathrm{t}, i}(k)\right\|_{Q_{\mathrm{F}}}^{2}+\left\|B C_{i}(k)\right\|_{Q_{\mathrm{C}}}^{2}
\end{gathered}
$$

\section{c. Constraints}

Define $\Delta t$ as the time of every control period. Then the available charge/discharge power can be expressed by,

$$
\begin{gathered}
P_{\mathrm{ESS}, i}^{\mathrm{charge}, \text { avi }}=\frac{\xi\left(S O C_{\mathrm{max}}-S O C_{i}\right) C_{\mathrm{ESS}}^{\mathrm{rated}, i}}{\Delta t} \\
P_{\mathrm{ESS}, i}^{\text {discharge }, \text { avi }}=\frac{\xi\left(S O C_{i}-S O C_{\mathrm{min}}\right) C_{\mathrm{ESS}}^{\mathrm{rated}, i}}{\Delta t}
\end{gathered}
$$

where $C_{\mathrm{ESS}}^{\mathrm{rated}, i}$ is the rated capacity of the $i$ th ESS, and $\xi=$ $\frac{1}{N_{p}}$ is a ratio for the available energy, which makes the ESSs sharing the same charge/discharge power limits at each control period. 
Consider the charge/discharge power limit of the DC/DC converter, the available charge/discharge power can be expressed as,

$$
P_{\mathrm{ESS}, i}^{\text {charge,max }}=\left\{\begin{array}{l}
P_{\mathrm{ESS}, i}^{\text {charge,avi }} \quad \text { if } P_{\mathrm{ESS}, i}^{\text {charge,avi }} \leq P_{\mathrm{ESS}}^{\lim } ; \\
P_{\mathrm{ESS}}^{\lim } \quad \text { if } P_{\mathrm{ESS}, i}^{\text {charg, avi }} \geq P_{\mathrm{ESS}}^{\lim } ;
\end{array}\right.
$$

$P_{\mathrm{ESS}, i}^{\text {discharge,max }}=\left\{\begin{array}{l}P_{\mathrm{ESS}, i}^{\text {discharge, avi }} \quad \text { if } P_{\mathrm{ESS}, i}^{\text {discharge,avi }} \leq P_{\mathrm{ESS}}^{\text {lim }} \\ P_{\mathrm{ESS}}^{\lim } \quad \text { if } P_{\mathrm{ESS}, i}^{\text {discharge, avi }} \geq P_{\mathrm{ESS}}^{\lim } ;\end{array}\right.$

where $P_{\mathrm{ESS}}^{\lim }$ is the power output limit of the ESS. For the wind farm, the total active power output should track the power reference from the TSO, such that,

$$
\sum_{i=1}^{\left|\mathcal{N}_{\mathrm{T}}\right|} P_{\mathrm{g}, i}+\sum_{i=1}^{\left|\mathcal{N}_{\mathrm{T}}\right|}\left(P_{\mathrm{ESS}, i}^{\mathrm{ch}}+P_{\mathrm{ESS}, i}^{\mathrm{dis}}\right)=P_{\mathrm{WF}}^{\mathrm{ref}}
$$

For a WT, the available power constraint is ,

$$
0 \leq P_{\mathrm{g}, i} \leq P_{\mathrm{W}, i}^{\mathrm{avi}}, \forall i \in \mathcal{N}_{\mathrm{T}} .
$$

where $P_{\mathrm{W}, i}^{\mathrm{avi}}$ is the available wind power of the $i$ th WT. For a distributed ESS, the charge/discharge power constraint is,

$$
\begin{aligned}
& 0 \leq P_{\mathrm{ESS}, i}^{\mathrm{ch}} \leq t_{i}^{\text {ch }} P_{\mathrm{ESS}, i}^{\text {charge,max }} \\
& 0 \leq P_{\mathrm{ESS}, i}^{\text {dis }, i} t_{i}^{\text {dis }} P_{\mathrm{ESS}, i}^{\text {discharge,max }}, \quad \forall i \in \mathcal{N}_{\mathrm{T}} .
\end{aligned}
$$

\section{B. Hierarchical active power control based on ADMM}

The MPC problem can be reformulated as a standard quadratic programming $(\mathrm{QP})$ problem such that it can be efficiently solved by commercial solvers in the central controller. However, when the wind farm comprises hundreds of WTs, the state space model of the wind farm becomes a large-scale model with large-scale constraints. To reduce the computation burden, a hierarchical control scheme based on the ADMM is proposed for the wind farm controller. Since the active power outputs of WTs are decoupled, the objective functions (23) and (24) can be distributed to each WT controller and calculated in parallel. Take the objective function of Mode 1 as an example. The ADMM algorithm solves the problems with,

$$
\begin{gathered}
\min \sum_{i=1}^{\left|\mathcal{N}_{\mathrm{T}}\right|} \sum_{k=1}^{N_{p}}\left\|C_{\mathrm{ESS}, \mathrm{i}}(k)-\alpha C_{\mathrm{ESS}}^{\mathrm{rated}}\right\|_{Q_{\mathrm{C}}}^{2}+\left\|\Delta T_{\mathrm{S}, i}(k)\right\|_{Q_{\mathrm{T}}}^{2} \\
+\left\|\Delta F_{\mathrm{t}, i}(k)\right\|_{Q_{\mathrm{F}}}^{2}+\left\|B C_{i}(k)\right\|_{Q_{\mathrm{C}}}^{2} \\
\text { subject to } u-z=0
\end{gathered}
$$

where $u$ is the decision variables vector optimized in the local controllers. $z$ is the decision variables vector optimized in the central controller. The argumented Lagrangian can be expressed by,

$$
\begin{aligned}
\min \sum_{i=1}^{\left|\mathcal{N}_{\mathrm{T}}\right|} \sum_{k=1}^{N_{p}} & \left\|C_{\mathrm{ESS}, \mathrm{i}}(k)-\alpha C_{\mathrm{ESS}}^{\mathrm{rated}}\right\|_{Q_{\mathrm{C}}}^{2}+\left\|\Delta T_{\mathrm{s}, i}(k)\right\|_{Q_{\mathrm{T}}}^{2} \\
& +\left\|\Delta F_{\mathrm{t}, i}(k)\right\|_{Q_{\mathrm{F}}}^{2}+\left\|B C_{i}(k)\right\|_{Q_{\mathrm{C}}}^{2} \\
& +y^{\mathrm{T}}(u-z)+\frac{\rho}{2}\|u-z\|_{2}^{2}
\end{aligned}
$$

where $y$ is the dual variable vector of the objective function, and $\rho$ is the penalty for the local variables that differ from the global variables. The augmented Lagrangian is also separable with respect to $u_{i}$. Then, for the $i$ th WT controller, the locally augmented Lagrangian can be expressed by,

$$
\begin{aligned}
\min \sum_{k=1}^{N_{p}} & \left\|C_{\mathrm{ESS}, \mathrm{i}}(k)-\alpha C_{\mathrm{ESS}}^{\mathrm{rated}}\right\|_{Q_{\mathrm{C}}}^{2}+\left\|\Delta T_{\mathrm{s}, i}(k)\right\|_{Q_{\mathrm{T}}}^{2} \\
& +\left\|\Delta F_{\mathrm{t}, i}(k)\right\|_{Q_{\mathrm{F}}}^{2}+\left\|B C_{i}(k)\right\|_{Q_{\mathrm{C}}}^{2} \\
& +y^{\mathrm{T}}\left(u_{i}-z_{i}\right)+\frac{\rho}{2}\left\|u_{i}-z_{i}\right\|_{2}^{2}
\end{aligned}
$$

The ADMM algorithm is an iterative algorithm. The flowchart of the algorithm is shown in Fig. 7.

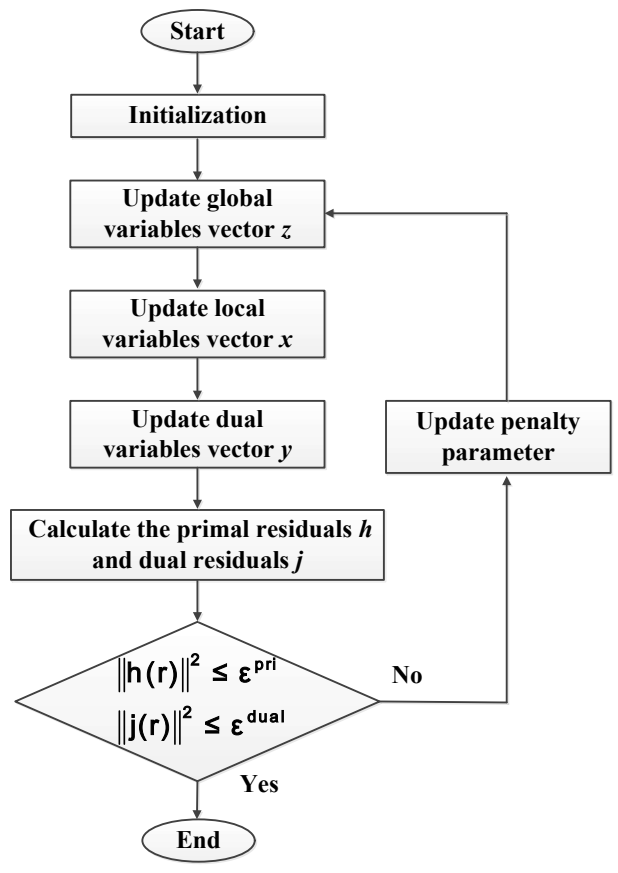

Fig. 7. The flowchart of the ADMM based HAPC.

The initial $u, z$, and $y$ are set to zero. $r$ is defined as the step of iteration, and each iteration consists of the following steps:

1) The wind farm central controller updates and solves the global optimization by using the augmented Lagrangian cost function with the global constraint, and it updates the global variables $z$, then,

$$
z(r+1)=\underset{z}{\arg \min } y^{\mathrm{T}}(r)(u(r)-z)+\frac{\rho}{2}\|u(r)-z\|_{2}^{2}
$$

subject to (29)

2) After updating $z$, the central controller sends $z_{i}$ to the corresponding WT controller through the communication network. Each WT local controller solves the local augmented Lagrangian problem with the local constraint in parallel, and then each controller solves the local optimization and updates 
local variable $u_{i}$. For the $i$ th WT controller,

$$
\begin{aligned}
u_{i}(r+1)=\underset{u_{i}}{\arg \min } & \sum_{k=1}^{N_{p}}\left\|C_{\mathrm{ESS}, \mathrm{i}}(k)-\alpha C_{\mathrm{ESS}}^{\mathrm{rated}}\right\|_{Q_{\mathrm{C}}}^{2} \\
& +\left\|\Delta T_{\mathrm{s}, i}(k)\right\|_{Q_{\mathrm{T}}}^{2}+\left\|\Delta F_{\mathrm{t}, i}(k)\right\|_{Q_{\mathrm{F}}}^{2} \\
& +\left\|B C_{i}(k)\right\|_{Q_{\mathrm{C}}}^{2}+y^{\mathrm{T}}(r)\left(u_{i}-z_{i}(r+1)\right) \\
& +\frac{\rho}{2}\left\|u_{i}-z_{i}(r+1)\right\|_{2}^{2} \\
& \text { subject to }(30),(31)
\end{aligned}
$$

The small-scale sub-optimization problem can be solved rapidly by using commercial optimization solver.

3) Update the dual variable $y_{i}$ in the local WT controller.

$$
y_{i}(r+1)=y_{i}(r)+\rho\left(u_{i}(r+1)-z_{i}(r+1)\right)
$$

To limit the online computation time and guarantee the accuracy of the calculation, a set of stopping criteria must be defined. Define the primal residuals $h$ and dual residuals $j$ as,

$$
\begin{array}{r}
h(r)=u(r)-z(r) \\
j(r)=\rho(z(r)-z(r-1))
\end{array}
$$

The primal and dual residuals must be maintained within a feasible range.

$$
\begin{gathered}
\|h(r)\|^{2} \leq \epsilon^{\mathrm{pri}} \\
\|j(r)\|^{2} \leq \epsilon^{\text {dual }}
\end{gathered}
$$

where $\epsilon^{\text {pri }}>0, \epsilon^{\text {dual }}>0$ are constants for the feasibility tolerances of the primal and dual feasibility conditions, respectively. To improve the convergence in practice, as well as to make the performance less dependent on the initial choice of the penalty parameter, $\rho$ is determined through a dynamic regulation approach according to primal and dual residuals. The varying penalty parameter can be expressed as,

$$
\rho(r+1)= \begin{cases}\vartheta \rho(r) & \text { if }\|h(r)\|^{2} \leq \kappa\|j(r)\|^{2} \\ \rho(r) / \varpi & \text { if }\|j(r)\|^{2} \leq \kappa\|h(r)\|^{2} \\ \rho(r) & \text { otherwise; }\end{cases}
$$

where $\vartheta>1, \varpi>1$, and $\kappa>1$ are coefficients. The binary variables in the iteration process are solved by using the method described in [35]. With part of the computation tasks distributed to the local WTs, the large-scale constrainted problem is decomposed. For the wind farm controller, the computation task is to calculate the objective function with equality constraints. When a wind farm consists of hundreds of WTs, the computation burden of the central controller can be considerably reduced. For the local WT controller, the computation task involves an optimization problem with smallscale constraints. The computation burden is not heavy for each WT controller.

\section{Case Study}

A wind farm with $30 \times 5 \mathrm{MW}$ DFIG WTs equipped with ESSs was used to validate the performance of the proposed control scheme. The wind farm control was carried out every $1 \mathrm{~s}$. The parameters of the test system are shown in the Appendix. To examine the performance of the proposed control method, the simulation results are compared with the ones based on the centralized active power control scheme (CAPC), the ones without ESSs [33], and the ones with the conventional proportional distribution (PD) control scheme.

\section{A. Dynamic Control Performance}

The performance of the proposed control scheme is tested, and WT8 is selected as the representative DFIG WT to illustrate the results. The total simulation time is set as $600 \mathrm{~s}$. Fig. 8 shows the total available wind power and the dispatch command from the TSO. The total available wind power fluctuates between 120 to $150 \mathrm{MW}$ from 0 to $280 \mathrm{~s}$. From 280 to $480 \mathrm{~s}$, the available wind power reaches the rated power. After $480 \mathrm{~s}$, the total available wind power gradually decreases. The dispatch command is set as $75 \mathrm{MW}$ from 0 to $250 \mathrm{~s}$. The wind farm operates in the constant power output mode. Then, the dispatch command increases within a ramping limit from 250 to $350 \mathrm{~s}$. The wind farm operates in the ramping mode. After $350 \mathrm{~s}$, the dispatch command is set as $150 \mathrm{MW}$. The wind farm operates in the MPPT mode. Fig. 9 shows the wind speed of WT8.

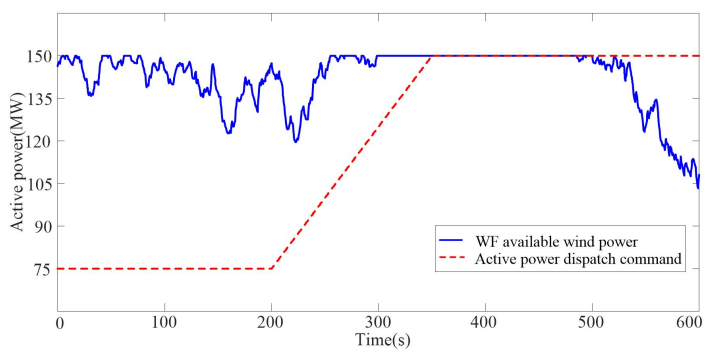

Fig. 8. Total available wind power and the dispatch command.

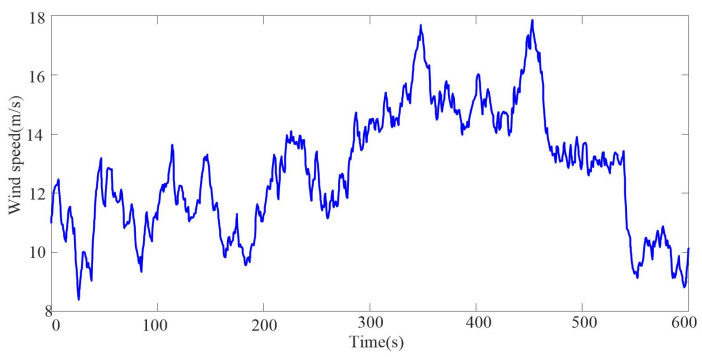

Fig. 9. Wind speed of WT8.

Figs. 10 and 11 show the variations of $T_{\mathrm{s}}$ and $F_{\mathrm{t}}$ of WT8. From 0 to $350 \mathrm{~s}$, the wind farm is operated in Mode 1 . The shaft torque variations with the HAPC are similar to those with the CAPC, and much smaller than those of the control scheme without ESSs. From 350 to $600 \mathrm{~s}$, the wind farm is operated in Mode 2. The performances with the HAPC and the CAPC are better than those without ESSs and the PD control scheme. From 560 to $600 \mathrm{~s}$, since all WTs are operated in the MPPT mode, the performances with the HAPC and CAPC are similar to the scheme without ESSs. The thrust force variations with the HAPC are similar to those with the CAPC and slightly smaller than those without ESSs and the PD control scheme. The total degradation costs of the ESSs are shown in Fig. 
12, which is compared with the ones without the ESS costbenefit optimization. With the cost-benefit optimization, the total degradation cost of the ESSs is reduced efficiently during the whole control period.

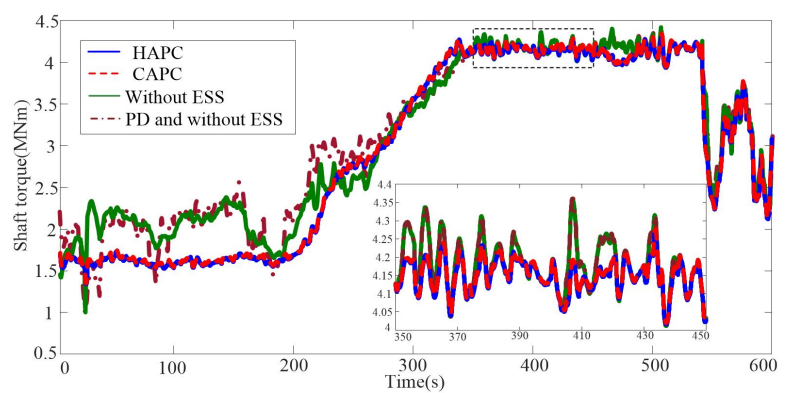

Fig. 10. Shaft torque of WT8.

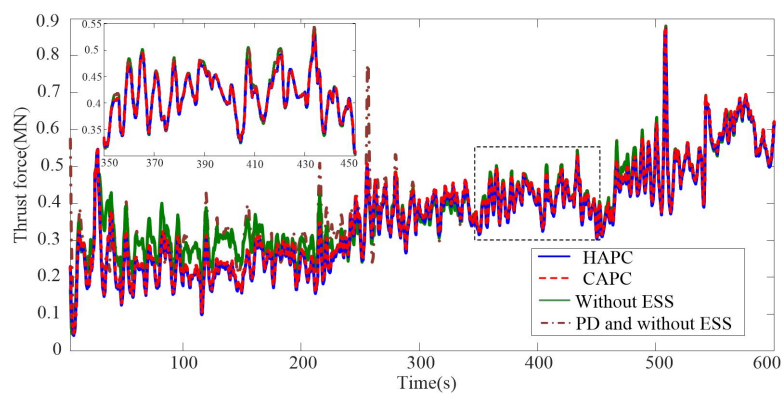

Fig. 11. Thrust force of WT8

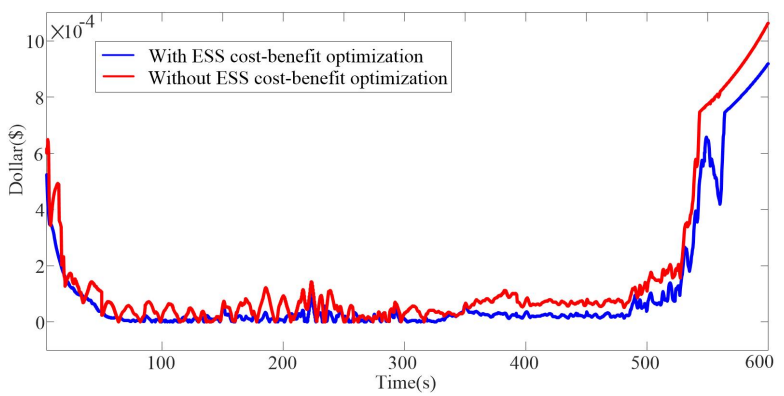

Fig. 12. Total degradation cost of ESSs.

Fig. 13 shows the SOC of ESSs. The SOC constraints are set in the range of 0.3-0.7. The initial SOCs of ESS 2-5, 7, and 8 are set as $0.55,0.57,0.65,0.56,0.61$, and 0.46 , respectively. The remaining initial SOCs are set as 0.6 . From 0 to $70 \mathrm{~s}$, all ESS SOCs converge to a common value. The SOCs fluctuate around approximately 0.6 from 0 to $350 \mathrm{~s}$. After $350 \mathrm{~s}$, since the ESSs discharge power to track the dispatch command, the SOCs decrease.

The output active power of WT8 and ESS8 is shown in Fig. 14. At the beginning, the ESS8 operates in the charge mode because the initial SOC is lower than the average SOC. The output power of the ESS is maintained between -1 and $1 \mathrm{MW}$. The active power outputs of WT8 with the HAPC are the same as those with the CAPC in the whole control period. Fig. 15 shows the output active power of the wind

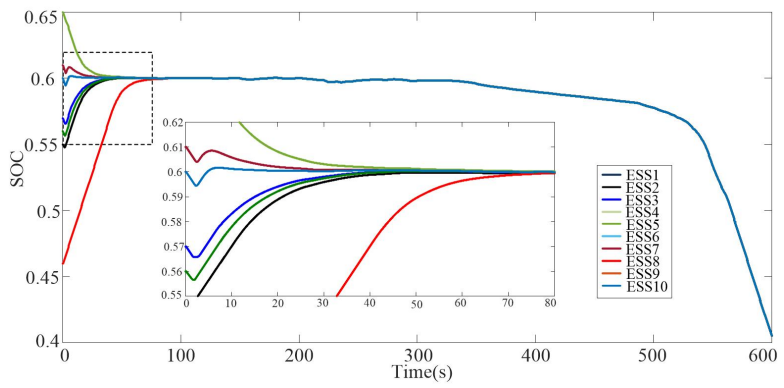

Fig. 13. SOC of ESSs.

farm. The wind farm with the HAPC can accurately track the dispatch command until the ESSs reach the active power output constraint. The performance of the scheme with the HAPC is similar to those with the CAPC. However, the HAPC scheme can substantially reduce the computation burden of the wind farm central controller, implying better computational efficiency than the other schemes.

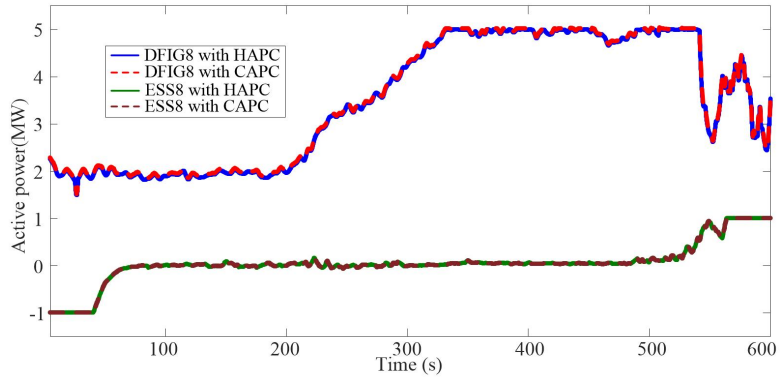

Fig. 14. Active power output of WT8 and ESS8.

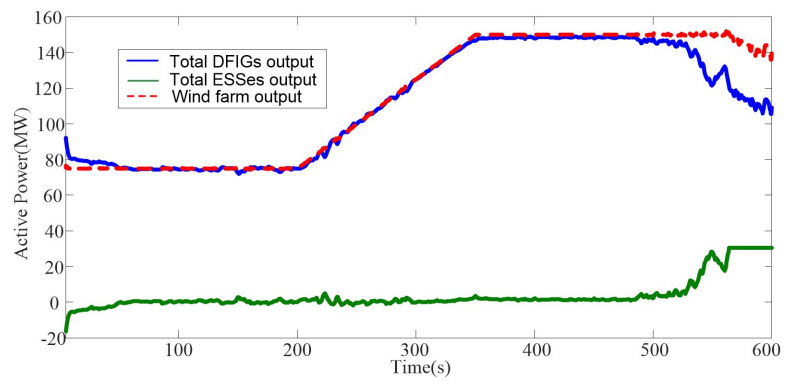

Fig. 15. Active power output of wind farm.

\section{B. Static Performance}

In this subsection, the static performance of the HAPC Scheme is validated. A dual decomposition methodbased HAPC is used to compare with the ADMM-based HAPC scheme, which is described in the Appendix. The charge/discharge power losses are neglected. The global variables $z_{1-8}$, local variables $u_{1-8}$ with the ADMM based HAPC and $x_{1-8}$ with the dual decomposition method based HAPC are selected as the representative variables to illustrate the convergence performances. Figs. 16-18 show the comparison of convergence performances between the ADMM and the 
TABLE I

THE COMPARISON OF CALCULATION TIME BETWEEN THE CAPC AND HAPC

\begin{tabular}{lllllll}
\hline & $30 \mathrm{WTs}$ & $100 \mathrm{WTs}$ & $200 \mathrm{WTs}$ & $300 \mathrm{WTs}$ & $400 \mathrm{WTs}$ & $500 \mathrm{WTs}$ \\
\hline Central controller with CAPC & $0.2761 \mathrm{~s}$ & $6.6863 \mathrm{~s}$ & $53.1587 \mathrm{~s}$ & $176.08 \mathrm{~s}$ & $412.67 \mathrm{~s}$ & $884.50 \mathrm{~s}$ \\
Central controller with HAPC & $0.0054 \mathrm{~s}$ & $0.0522 \mathrm{~s}$ & $0.3114 \mathrm{~s}$ & $0.9861 \mathrm{~s}$ & $2.1209 \mathrm{~s}$ & $4.0740 \mathrm{~s}$ \\
WT controller with HAPC & $0.0043 \mathrm{~s}$ & $0.0043 \mathrm{~s}$ & $0.0043 \mathrm{~s}$ & $0.0043 \mathrm{~s}$ & $0.0043 \mathrm{~s}$ & $0.0043 \mathrm{~s}$ \\
Iteration number with HAPC & 24 & 28 & 32 & 33 & 33 & 34 \\
Total computation time of central controller with HAPC & $0.1296 \mathrm{~s}$ & $1.4616 \mathrm{~s}$ & $9.9648 \mathrm{~s}$ & $32.541 \mathrm{~s}$ & $69.99 \mathrm{~s}$ & $138.52 \mathrm{~s}$ \\
Total computation time with HAPC & $0.2328 \mathrm{~s}$ & $1.582 \mathrm{~s}$ & $10.1024 \mathrm{~s}$ & $32.683 \mathrm{~s}$ & $70.132 \mathrm{~s}$ & $138.66 \mathrm{~s}$ \\
Reduced percentage with HAPC & $-15.68 \%$ & $-76.34 \%$ & $-81.00 \%$ & $-81.44 \%$ & $-83.00 \%$ & $-84.32 \%$ \\
\hline
\end{tabular}

dual decomposition method for the HAPC problem. It can be seen that the ADMM shows much better convergence than the dual decomposition method. The local variables $u_{1-8}$ and their corresponding global variable $z_{1-8}$ converge to the same value and obtain the optimal solution within about 25 iterations, implying fast convergence. The dual decomposition method converges to the optimal solution after about 250 iterations with $\alpha=0.0015$. When $\alpha=0.0017$, the dual decomposition method fails to converge to the optimal solution.

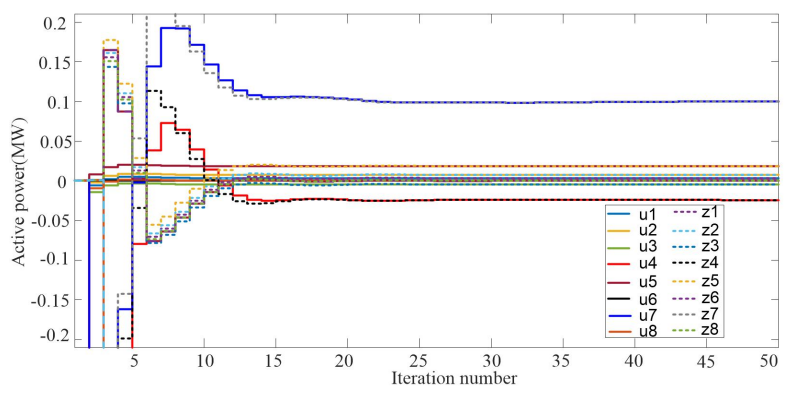

Fig. 16. Convergence performance with the ADMM.

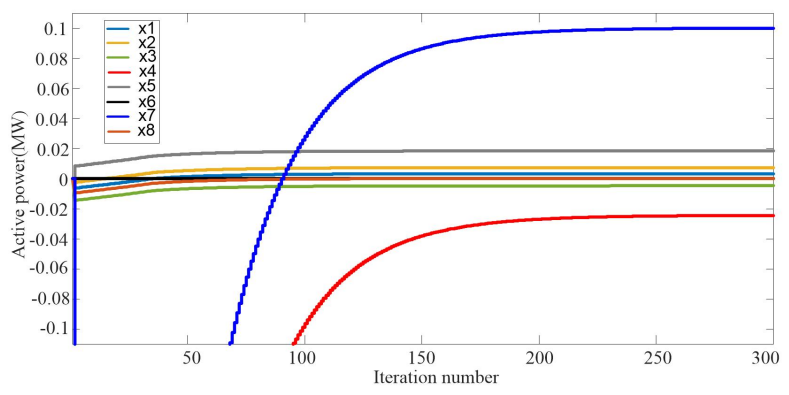

Fig. 17. Convergence performance with the dual decomposition method ( $\alpha$ $=0.0015$ ).

Fig. 19 shows the performance of the converge rate. $u_{2}$ is selected as a representative variable to illustrate the results. In Fig. 19, when the iteration number reaches 100, the converge rate of $u_{2}$ close to zero. $u_{2}$ converges superlinearly.

The calculation time of the CAPC scheme and HAPC scheme with 30 WTs, 100 WTs, 200 WTs, 300 WTs, 400 WTs, and 500 WTs has been tested. The HAPC and CAPC schemes were implemented in the MATLAB R2016a. The ADMM based HAPC scheme was tested using a serial implementation on a single-core. The comparison of the calculation time of the CAPC and HAPC schemes is listed at Table I.

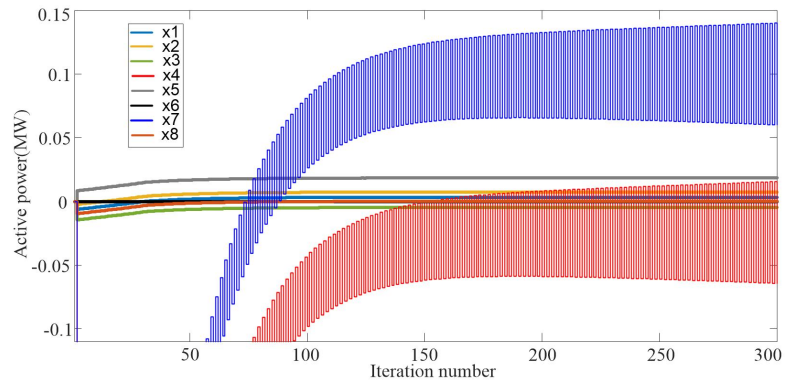

Fig. 18. Convergence performance with the dual decomposition method ( $\alpha$ $=0.0017$ ).

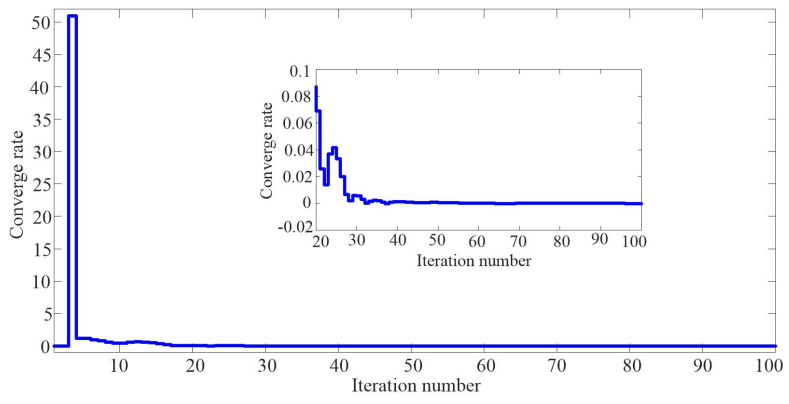

Fig. 19. Converge rate of $u_{2}$.

In the CAPC scheme, the computation task of the central controller includes the parameters calculation, the matrixes calculation of the MPC-based optimization problem, and the QP optimization problem solution by using solver. In Table I, the calculation time of the central controller with the CAPC is rapidly increased with the number increase of WTs. When the number of WTs reaches 500, the calculation time is 884.50 $\mathrm{s}$, which has a $3202 \%$ increase compare to a wind farm with 30 WTs. In the ADMM based HAPC, the calculation time is much smaller than that with the CAPC. The iteration number with the HAPC is not sensitive to the number of WTs. When a wind farm consists of $30 \mathrm{WTs}$, the iteration number is 24 . When the number of WTs reaches 500, the iteration number is 34 , only 10 more iterations required. Consider the iteration number of the HAPC, the total calculation time of the central controller with the HAPC is still much smaller than that with the CAPC. For the local WT controller with the HAPC, the calculation time is $0.0043 \mathrm{~s}$ for one step calculation. And the calculation time will not increase with the increase of WTs number. When a wind farm consists of 30 WTs, the total 
calculation time with the HAPC is $0.2328 \mathrm{~s}$, which is $15.58 \%$ lower compared to the CAPC (0.2761 s). When the number of WTs reaches 500, the total calculation time with the HAPC is $138.66 \mathrm{~s}$, which is $84.32 \%$ lower compared to the CAPC (884.50 s). Therefore, the computation burden can be largely reduced with the HAPC.

\section{CONCLUSION}

In this paper, the HAPC scheme based on the ADMM is proposed for the DFIG-based wind farm with distributed ESSs. The centralized optimal control scheme based on the MPC is formulated as a hierarchical control scheme by using the ADMM algorithm, aiming to reduce the computation burden of the wind farm central controller. As verified by the case studies, the control scheme can efficiently reduce the fatigue loads of WTs while tracking the dispatch command from the TSO. Moreover, the SOC of each ESS is maintained within the feasible range. The computation burden of the wind farm central controller can be largely reduced with the HAPC. The proposed hierarchical optimal power control scheme can effectively solve the QP problem in a hierarchical manner without loss of optimality of the primal problem.

\section{REFERENCES}

[1] F. Daz-González , A. Sumper, O. Gomis-Bellmunt, and R. VillafáfilaRobles, "A review of energy storage technologies for wind power applications," Renew. and sust. energy rev., vol. 16, no. 4, pp. 2154-2171, 2012.

[2] R. Perveen , N. Kishor, and S. R. Mohanty, "Off-shore wind farm development: Present status and challenges," Renew. and Sustain. Energy Rev., vol. 29, pp. 780-792, 2014.

[3] P. K. Dash, R. K. Patnaik, and S. P. Mishra, "Adaptive fractional integral terminal sliding mode power control of UPFC in DFIG wind farm penetrated multimachine power system," Protection and Control of Modern Power Syst., vol. 3, no. 3, pp. 79-92, 2018

[4] R. Hemmati, "Optimal design and operation of energy storage systems and generators in the network installed with wind turbines considering practical characteristics of storage units as design variable," Journal of Cleaner Production, vol. 185, pp. 680-693, 2018.

[5] H. Zhao, Q. Wu, S. Hu, H. Xu, and C. N. Rasmussen, "Review of energy storage system for wind power integration support," Applied Energy, vol. 137, pp. 545-553, 2015.

[6] J. L. Domínguez-García, O. Gomis-Bellmunt, F. D. Bianchi, and A. Sumper, "Power oscillation damping supported by wind power: A review," Renew. and Sust. Energy Rev., vol. 16, no. 7, pp. 4994-5006, 2012.

[7] J. Li, S. Wang, L. Ye, and J. Fang, "A coordinated dispatch method with pumped-storage and battery-storage for compensating the variation of wind power," Protection and Control of Modern Power Syst., vol. 3, no. 1, pp.21-34, 2018.

[8] H. Zhao, Q. Wu , Q. Guo, H. Sun, and Y. Xue, "Distributed model predictive control of a wind farm for optimal active power controlpart II: Implementation with clustering-based piece-wise affine wind turbine model," IEEE Trans. Sustain. Energy, vol. 6, no. 3, pp. 840-849, Jul. 2015.

[9] W. Li, G. Joós, and J. Bélanger, "Real-Time Simulation of a Wind Turbine Generator Coupled With a Battery Supercapacitor Energy Storage System," IEEE Trans. Ind. Electr., vol. 57, no. 4, pp. 1137-1145, Apr. 2010.

[10] L. Qu and W. Qiao, "Constant power control of DFIG wind turbines with supercapacitor energy storage," IEEE Trans. Ind. Appli., vol.47, no. 1, pp. 359-367, Jan./Feb. 2011.

[11] B.Ge, W. Wang, D. Bi, C. B. Rogers, F. Peng, A. T. de Almeida, and H. Abu-Rub, "Energy storage system-based power control for grid-connected wind power farm," Int. Jour. of Electr. Power and Energy Syst.,vol. 44, no. 1, pp. 115-122, 2013.

[12] W. Li, and G. Joós, "Performance comparison of aggregated and distributed energy storage systems in a wind farm for wind power fluctuation suppression," in proc. IEEE Power Engineering Soc. Gener. Meeting, 2007, pp. 1-6.
[13] M. Vasiladiotis and A. Rufer, "Analysis and control of modular multilevel converters with integrated battery energy storage," IEEE Trans. Power Electr., vol. 30, no. 1, pp. 163-175, Jan. 2015.

[14] F. Gao, L. Zhang, Q. Zhou, M. Chen, T. Xu, and S. Hu, "State-ofcharge balancing control strategy of battery energy storage system based on modular multilevel converter," in proc. IEEE Energy Conver. Congress and Expos., 2014, pp. 2567-2574.

[15] N. Mendis, K. M. Muttaqi, and S. Perera, "Management of batterysupercapacitor hybrid energy storage and synchronous condenser for isolated operation of PMSG based variable-speed wind turbine generating systems," IEEE Trans. smart grid, vol. 5, no. 2, pp. 944-953, Mar. 2014.

[16] R. Sarrias, L. M. Fernández, and C. A. García,"Coordinate operation of power sources in a doubly-fed induction generator wind turbine/battery hybrid power system," Journal of Power Sources, vol. 205, pp. 354-366, 2012.

[17] Y. Guo, H. Gao, H. Xing, Q. Wu, and Z. Lin,"Decentralized Coordinated Voltage Control for VSC-HVDC Connected Wind Farms Based on ADMM," IEEE Trans. Sustain. Energy, in press, 2018.

[18] J. B. Berglind, R. Wisniewski, and M. Soltani, (2015, July), "Fatigue load modeling and control for wind turbines based on hysteresis operators," in proc. IEEE American Contr. Conf., 2015, pp. 3721-3727.

[19] D. Madjidian, K. Mårtensson, and A. Rantzer, "A distributed power coordination scheme for fatigue load reduction in wind farms, in Proc. IEEE American Contr. Conf., 2011, pp. 5219-5224.

[20] V. Spudić, "Coordinated optimal control ofwind farm active power," Ph.D. dissertation, Dept. Control Comput. Eng., Univ. Zagreb, Zagreb, Croatia, 2012.

[21] I. Munteanu, Optimal control of wind energy systems: towards a global approach, Springer, London, 2008.

[22] F. M. Ebrahimi, A. Khayatiyan, and E. Farjah, "A novel optimizing power control strategy for centralized wind farm control system," Renew. Energy, vol. 86, pp. 399-408, 2016.

[23] V. Spudić, M. Baotić, and N. Perić, "Wind farm load reduction via parametric programming based controller design," Int. Federation of Auto. Cont., 2011, pp. 1704-1709.

[24] V. Spudić,, M. Jelavić,, and M. Baotić, "Wind turbine power references in coordinated control of wind farms," Automatika, vol. 52, no. 2, pp 82-94, 2011.

[25] H. Zhao, Q. Wu, J. Wang, Z. Liu, M. Shahidehpour, and Y. Xue, "Combined active and reactive power control of wind farms based on model predictive control," IEEE Trans. Energy Conver, vol. 32, no. 3, pp. 1177-1187, Sep. 2017.

[26] H. Zhao, Q. Wu, S. Huang, M. Shahidehpour, Q. Guo, and H. Sun, "Fatigue load sensitivity-based optimal active power dispatch for wind farms," IEEE Trans. Sustain. Energy, vol. 8, no. 3, pp. 1247-1259, Jul. 2017.

[27] T. Erseghe, "Distributed optimal power flow using ADMM," IEEE trans. power syst., vol. 29, no. 5, pp. 2370-2380, Sep. 2014.

[28] S. Magnússon, P. C. Weeraddana, and C. Fischione, "A distributed approach for the optimal power-flow problem based on ADMM and sequential convex approximations," IEEE Trans. Contr. of Net. Syst., vol. 2, no. 3, pp. 238-253, Sep. 2015.

[29] C. Wessels, F. Gebhardt, and F. W. Fuchs, "Fault ride-through of a DFIG wind turbine using a dynamic voltage restorer during symmetrical and asymmetrical grid faults," IEEE Trans. Power Electr., vol. 26, no. 3, pp. 807-815, Mar. 2011.

[30] A. Merabet, K. T. Ahmed, H. Ibrahim, R. Beguenane, and A. M. Ghias,"Energy management and control system for laboratory scale microgrid based wind-PV-battery," IEEE Trans. Sustain. Energy, vol. 8, no. 1, pp. 145-154, Jan. 2017.

[31] B. Zhou, D. Xu, C. Li, C. Y. Chung, Y. Cao, K. W. Chan, and Q. Wu, "Optimal scheduling of biogas-solar-wind renewable portfolio for multicarrier energy supplies," IEEE Trans. Power Syst., vol. 33, no. 6, pp. 6229-6239, Nov. 2018.

[32] J. D. Grunnet, M. Soltani, and T. Knudsen, "Aeolus toolbox for dynamics wind farm model, simulation and control," The European Wind Energy Conf. Exh., EWEC, 2010.

[33] S. Huang, Q. Wu, Y. Guo and Z. Lin, "Bi-level decentralised active power control for large-scale wind farm cluster," IET Renew. Power Gener, vol. 12, no. 13, pp. 1486-1492, 2018.

[34] J. M. Maciejowski, Predictive control: with constraints, Pearson education, 2002.

[35] R. Takapoui, N. Moehle, S. Boyd, and A. Bemporad, "A simple effective heuristic for embedded mixed-integer quadratic programming," Int. Jour of Control, pp. 1-11. 2017. 

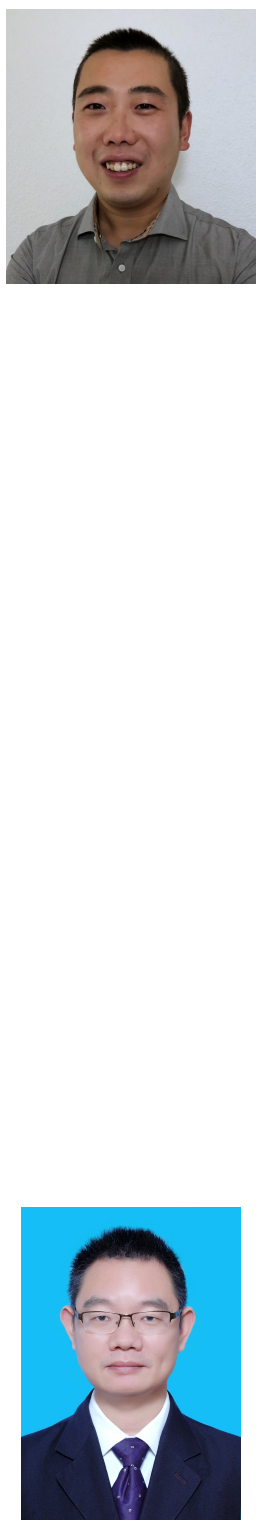

Sheng Huang received the M.S. and Ph.D. degree both in College of Electrical and Information Engineering, Hunan University, Changsha, China, in 2012 and 2016, respectively. He is currently a Postdoc with the Center for Electric Power and Energy, Technical University of Denmark. His research interests include renewable energy generation, modeling and integration study of wind power, control of energy storage system, and voltage control.

Fei Rong was born in Hubei, China, in 1978. He received the B.S. and M.S. degrees from Central South University, Changsha, China, in 2000 and 2003, respectively. $\mathrm{He}$ also received $\mathrm{Ph} . \mathrm{D}$. degree from Hunan University, Changsha, China, in 2008.He was a lecture from 2008 to 2010, and since 2011, has been an Associate Professor of electrical engineering in the College of Electrical and information engineering, Hunan University. His interests include distributed power generation, reactive power compensation and active power filters. 